\title{
Long Memory in Asymmetric Volatility of Asean Exchange-Traded Funds
}

\author{
Maya Malinda
}

\begin{abstract}
This research applied closing price return for ASEAN ETFs. Comparing the long memory in volatility and asymmetric volatility of ASEAN ETFs, this research used four models, fractional autoregressive integrated moving average (ARFIMA), a hybrid of ARFIMA and fractionally integrated generalized autoregressive conditional heteroscedasticity (ARFIMA-FIGARCH), ARFIMA with fractionally integrated asymmetric power autoregressive conditional heteroscedasticity (ARFIMA-FIAPARCH) and ARFIMA with hyperbolic generalized autoregressive conditional heteroscedasticity (ARFIMA-HYGARCH) models. The results show that by using closing price return data samples ASEAN ETF have a long memory in volatility and negative asymmetric volatility. ARFIMA-FIAPARCH model perform better to investigate long memory in volatility and asymmetric volatility for ASEAN ETF. This findings can be evaluated by academicians, financial risk managers, investors, and regulators.
\end{abstract}

Index Terms-Long memory in volatility, asymmetric volatility, ASEAN ETF.

\section{INTRODUCTION}

Exchange-traded fund (ETF) has grown significantly since 1993. ETFs was launched for the first time by State Street Global Advisors. For more than twenty years volatility and correlations in ETFs have increased over the past few years, however, these conditions always challenge and opportunity for investors to get profit from investing ETFs. That's the reason why the risks have caused markets to function in a different way. In particular, correlation risk with ETFs has connected the large fluctuations in volatility and enhanced in the equity market. Mazza revealed that a good advantage of investing in ETFs that displayed correlations and higher volatility [1].

There are several motivations of this research. First, this work examines closing price return ETFs in order to find long memory and the asymmetric volatility in ASEAN ETFs. Next is to reveal the best model among ARFIMA, ARFIMA-FIEGARCH, ARFIMA-FIAPARCH and ARFIMA-HYGARCH models to find long memory and the asymmetric volatility.

The contribution of this study revealed that closing price return for ASEAN ETFs have long memory and asymmetric volatility. Furthermore, this paper found that there are long memory and the asymmetric volatility of ASEAN ETF. Finally, this study also revealed that ARFIMA-FIAPARCH is the best model to explain long memory and the asymmetric volatility, among others.

Manuscript received January 10, 2017; revised March 15, 2017.

Maya Malinda is with the Universitas Kristen Maranatha (Maranatha Christian University), Indonesia (e-mail: hmy.malinda@yahoo.com).
This article is organized in five sections. Section II presents the literature review. Section III describes the data and explains ARFIMA, ARFIMA-FIEGARCH, ARFIMAFIAPARCH and ARFIMA-HYGARCH models. Section IV presents the empirical results of the ETF for long memory and asymmetric volatility of ASEAN ETFs, and Section V provides the conclusion.

\section{LITERATURE REVIEW}

Schoenfeld mentioned that ETFs can be one or a diversification of investment. The global investment market has witnessed a sudden increase in the number and capitalization of ETFs [2]. Gao explained that the reasons for this expansion were diversification, convenience, simplicity, cost-effectiveness, transparency, flexibility, taxefficiency, and variety. ETFs have certainly caught investors' attention on the many available investment opportunities that surfaced from their home markets [3].

Many economists and researcher have interested about the models to examine long memory in time series data. The example of ARFIMA model studied by Granger; Granger and Joyeux; Hosking etc [4]-[7]. Actually, Engle is the first to propose an ARCH model of conditional volatility [8]. Thus, expanding with many models, GARCH model created by Bollerslev, the IGARCH develop by Engle and Bollerslev, and the FIGARCH model proposed by Baillie $e t$ al., [9]-[11]. Moreover, FIEGARCH model proposed by Bollerslev and Mikkelsen [12]. More recently, Davidson was proposed HYGARCH model, and argued that original long memory compared with FIGARCH model was more flexible than IGARCH and FIGARCH models [14].

Gutierrez et al. found different return and volatility of Asian ETFs which traded in the United States [15]. Liu et al. forecasted volatility and value at risk SPDRs with GARCH, IGARCH, EGARCH models [16]. They found that EGARCH model revealed asymmetric volatility, thus IGARCH/EGARCH can used for shorter/longer trading period. Moreover, GARCH model may over-predict volatility, providing adequate value at risk forecast. By using ARFIMA-FIGARCH models, found that no significant long memory process can be found between Green ETFs [17]. Ruiz and Viega used A new stochastic volatility model (A-LMSV) and FIEGARCH models and found leverage effect and long memory in volatility of the daily return of the Standard \& Poor 500 S\&P 500 and Deutscher Aktien IndeX (DAX) indexes [18], [19]. Tang and Shieh revealed that HYGARCH model was outperformed for investigate the long memory for the S\&P 500, Nasdag 100 and futures prices [20]. Pelinescu and Acatrine revealed that there is have a long memory process 
in the exchange rate in Romania with FIGARCH model [21].

Wiphatthanananthakula and Sriboonchitta found that FIAPARCH is longer memory than FIGARCH to capture asymmetric effect [22].

Even though many research studies about long memory, forecasting and asymmetric volatility ETFs, however, as my knowledge not many specific research concern the long memory properties with ASEAN ETF. Moreover, this study tends to prove that there is have any difference between ARFIMA, ARFIMA-FIEGARCH, ARFIMA- FIAPARCH and ARFIMA-HYGARCH models to reveal long memory exist in ASEAN ETFs.

\section{DATA AND METHODOLOGY}

This research uses daily closing prices ASEAN ETFs This study uses ARFIMA, ARFIMA-FIGARCH, ARFIMAFIAPARCH and ARFIMA-HYGARCH models.

\section{A. Autoregressive Fractionally Integrated Moving Average (ARFIMA)}

The autoregressive moving average model ARMA $(p, q)$ proposed by Box and Pierce to illustrate the stationary time series, where $p$ is the autoregressive item and $q$ is the moving average item. The Autoregressive Integrated Moving Average Model ARIMA $(p, d, q)$ that used parameter $\mathrm{d}$ to differentiate the time series variables to let the variables turning to stationary [23].

The ARFIMA model proposed by Granger and Joyeux, which allows the parameter $d$ to be the non-integer or fraction. If there is $0<d<0.5$, it will represent the time series with long memory effect [24]. The mathematical model ARFIMA (p, d, q) is defined as below:

$$
\Phi(L)(1-L)^{d}\left(y_{t}-\mu_{t}\right)=\Psi(L) \varepsilon_{t},
$$

where $d$ represent the fractional integration, real number parameter, $\mathrm{L}$ is the lag operator, and $\varepsilon_{t}$ is a noise residual.

$\Phi(L)=1-\Phi_{1} L-\cdots-\Phi_{p} L^{p}=1-\sum_{j=1}^{p} \Phi_{j} L^{j}$ are the polynomials in the lag operator of order p, $\Psi(\mathrm{L})=1+$ $\sum_{j=1}^{p} \Psi_{j} L^{j}$ are the polynomials in the lag operator of order $q$ where both $\mathrm{p}$ and $\mathrm{q}$ are integer. $\varepsilon_{t}$ is a Gaussian white noise with variance 1 , and $\mu_{t}$ is $\mathrm{y}_{\mathrm{t}}$ 's mean.

The fractional differencing lag operator $(1-L)^{d}$ can be further illustrated by using the expanded equation below:

$$
(1-L)^{d}=1-d L+\frac{d(d-1)}{2 !} L^{2}-\frac{d(d-1)(d-2)}{3 !} L^{3}+
$$

Based on Paul et al., when $d=0$, then the variable has short memory and the effect of shocks to $\varepsilon_{\mathrm{t}}$ decays faster (geometric decay). When $-0.5<d<0.5$, the variable is stationary, wherein the effect of market shocks to $\varepsilon_{\mathrm{t}}$ decays at a gradual rate to zero (hyperbolic decay). When $d=1$, there is the presence of a unit root process [24].

Furthermore, Hsieh and Lin showed that there is an intermediate memory when $-0.5<d<0$, representing that the autocorrelation function decays slower [25]. There is a short memory when $d=0$, the Autocorrelation function decays faster. If there is $0<d<0.5$, it represents the time series with long memory effect. The time series variable is nonstationary when $d \geq 0.5$, at the same time as the time series variable is stationary when $d \leq 0.5$.

\section{B. ARFIMA Fractionally Integrated Generalized} Autoregressive Conditional Heteroskedasticity ARFIMAFIGARCH

This research used daily data ASEAN ETFs from yahoo.finance.

The methodology designed for this research is the estimation of a long memory use ARFIMA and FIGARCH models

Based on Hosking, Paul et al., Hsieh and Lin when, -0.5 $<d<0.5$, the $y_{t}$ process is stationary and invertible, for some processes the effect of shocks to $\varepsilon_{t}$ on $y_{t}$ decay at the slow rate to zero [7], [24], [25]. When $d=0$ the process is stationary, means variable has short memory, and the effect of the shocks to $\varepsilon_{t}$ on $y_{t}$ decay geometrically. While $d=1$, there is the presence of a unit root process, then and the effect of shocks to $\varepsilon_{\mathrm{t}}$ decays faster. When $0<d<0.5$ the process exhibits positive dependence between distant observations implying long memory. When $-0.5<d<0$, process exhibits negative dependence between distant observations, so called anti persistent. In general, the empirical results express that ARFIMA model has improved presentation in predict volatility. Sivakumar and Mohandas found that ARFIMA model's predictive power is reasonably good compared to ARMA and ARIMA [11].

Fractional Integrated Generalized Autoregressive Conditional Heteroskedasticity model (FIGARCH) proposed by Baillie et al., Kang and Yoon confines the long memory in volatility return. The $\operatorname{FIGARCH}(p, d, q)$ model can be expressed as follows [12], [14]:

$$
\phi(L)(1-L)^{d} \varepsilon_{t}^{2}=\omega+[1-\beta(L)] v_{t}
$$

where $\quad \phi(L) \equiv \phi_{1} L+\phi_{2} L^{2}+\cdots+\phi_{q} L^{q}, \beta(L) \equiv \beta_{1} L+$ $\beta_{2} L^{2}+\cdots+\beta_{p} L^{p}$ and $v_{t} \equiv \varepsilon_{t}^{2}-\sigma_{t}^{2}$. The $v_{t}$ process can be interpreted as the innovations for the conditional variance and has zero mean serially uncorrelated. All the root of $\phi(L)$ and $[1-\beta(L)]$ lie outside the unit root circle. FIGARCH model explains, for $0<d<1$ means intermediate range of persistence. When $-0.5>d>0.5$, the series is stationary, wherein the effect of market shocks decays at a gradual rate to zero. If $d=0$, the series has short memory and the effect of shocks decays geometrically. When $d=1$, there is the presence of a unit root process [26][28].

\section{ARFIMA-Fractionally Integrated Asymmetric Power} Autoregressive Conditional Heteroskedasticity (ARFIMAFIAPARCH)

Asymmetric power ARCH (APARCH) model of Ding et $a l$. and then continue by Tse to fractionally integrated of Baillie et al [29]-[30], [12]. Which is extended to FIAPARCH model as follows:

$$
\sigma_{t}^{\delta}=\omega+\left[1-\frac{[1-\phi(L)](1-L)^{d}}{1-\beta(L)}\right]\left[\left|v_{t}\right|-\gamma v_{t}\right]^{\delta}
$$

where $0<d<1, \omega, \delta>0, \varphi, \beta<1,-1<\gamma<1$ and $L$ is the lag operator. When $\gamma>0$, negative shocks have a higher volatility than positive shocks. The particular value of power term may lead to sub optimal modeling and forecasting performance. Ding et al. found that the closer of d value converge to 1 , the larger the memory of the process becomes [19]. 
The process of FIAPARCH allows for asymmetry. When $\gamma=0$ and $\delta=2$, the process of FIAPARCH is reduced to FIGARCH process.

ARFIMA-FIAPARCH generates the long memory property in both the first and (power transformed) second conditional moments and is sufficiently flexible to handle the dual long memory behavior. ARFIMA-FIAPARCH model can recognize the long memory and provides an empirical measure of real uncertainty that accounts for long memory in the power transformed conditional variance of the process.

\section{ARFIMA-Hyperbolic Generalized Autoregressive Conditional Heteroskedasticity (ARFIMA- HYGARCH)}

Ruiz and Vega, revealed that unexpected behavior of the FIGARCH model, perhaps due to any inherent paradoxes less than to the fact that the unit-amplitude restriction, has been transplanted into a model of volatility. In contrast with FIGARCH model, HYGARCH allows combining the desired properties of hyperbolically decaying impulse response coefficients and covariance stationary [18].

Davidson proposed the HYGARCH $(r, d, s)$ model as follow [14]:

$$
\left.\theta(L)=1-\frac{\delta(L)}{\beta(L)}\left(1+\alpha(1-L)^{d}-1\right)\right) \alpha \geq 0, d \geq 0,
$$

where $\delta(L) / \beta(L)$ is comparison between hyperbolic decay and geometric decay, when $\delta(L) / \beta(L)>0$. When $\alpha<1$, these processes are covariance stationary, where $L$ is the lag operator. Ding and Granger explains HYGARCH model is more flexibility in long-run component of modelling the degree of persistence via the memory parameter $d$ [29].

When $d>0$, the equation reduces to

$$
S=1-\frac{\delta(1)}{\beta(1)}(1-\alpha)
$$

Davidson, FIGARCH and stable GARCH happen when $\alpha=1$ and $\alpha=0$, and it means non stationary when $\alpha>1$ [14].

When $d>1$, there is an indication to negative coefficient, which is not permitted.

When $d=1$, the equation reduces to

$$
\theta(L)=1-\frac{\delta(L)}{\beta(L)}(1+\alpha L) \quad \alpha \geq 0 .
$$

Noted that, the parameter $\alpha$ reduce to an autoregressive root when $d=1$, ad $\mathrm{t}$ becomes a stable GARCH or IGARCH depending on $\alpha<1$ or $\alpha=1$. Testing the restriction $d=1$ is the natural way to test geometric and hyperbolic memory, and $\alpha>1$ is also a legitimate case of nonstationary.

When $d$ is not too large, then

$$
\theta(L)=1-\frac{\delta(L)}{\beta(L)}(1-\alpha \emptyset(L))
$$

where

$$
\emptyset(L)=\zeta(1+d)^{d-1} \sum_{j=1}^{\infty} j^{-1-d} L^{j}, d>0,
$$

$\zeta($.$) is Riemann zeta function.$

Kwan et al. said that, when $0<d \leq 1$, it means hyperbolic decaying memory and geometric decaying memory with the former being defined as long memory, then $d=1$, the conditional variance model becomes an ordinary GARCH model [32].

\section{RESUlts}

The results in Table I showed that form 1134 days observation ASEAN ETFS have negative mean and high standard deviation. For ASEAN ETFs have negative skewness and leptokurtic distribution. Their means have high risk to invest in ASEAN ETFs. The significant JarqueBera Statistic for residual normality shows that ASEAN ETFs are under a non-normal distribution.

This research uses the minimum Akaike Information Criterion (AIC) to classify the orders of ARFIMA, ARFIMA-FIEGARCH and ARFIMA-HYGARCH models. This study used the ARCH Lagrange Multiplier Test (ARCH-LM) to test the ARCH effect. For testing unit root

\begin{tabular}{|c|c|c|c|c|c|c|c|}
\hline Code & $\begin{array}{c}\text { Inception } \\
\text { Periode }\end{array}$ & Obs. & Mean & $\begin{array}{l}\text { Std. } \\
\text { Dev. }\end{array}$ & Skew. & Kurt. & J-Bera \\
\hline ASEA & $2 / 18 / 2011$ & 1134 & -0.006 & 0.524 & -0.317 & 3.649 & $648.49 * * *$ \\
\hline
\end{tabular}
makes clear for the variables having stationary or nonstationary, and this research uses Augmented Dickey Fuller (ADF) proposed by Dickey and Fuller [31].

TABLE I: THE DESCRIPTIVE STATISTICS OF VARIABLES

In Table II, ASEAN ETF have significant ADF test, results shows stationary and appropriate for further testing. This study applied the minimum value of AIC to identify the optimal model of ARMA. By using the Q test, this study observes whether the residuals have series correlation or not. The results showed that insignificant accept the null hypothesis of no autocorrelation. Engle mentions to test the ARCH effect, this paper uses the ARCH-Lagrange Multiplier test (ARCH-LM) [8]. The results showed that all rejected the null hypothesis, indicating that sample have heteroscedasticity. For eliminate heteroscedasticity this research continue to use GARCH model $(1,1)$ and then the

\begin{tabular}{|c|c|c|c|c|c|c|c|c|}
\hline Code & $\mathrm{ADF}$ & \begin{tabular}{|c|} 
ARM \\
A
\end{tabular} & AIC & Q test & $\begin{array}{c}\text { ARCH- } \\
\text { LM }\end{array}$ & $\begin{array}{c}\text { GAR } \\
\mathrm{CH}\end{array}$ & AIC & \begin{tabular}{|c|} 
ARCH- \\
LM
\end{tabular} \\
\hline ASEA & $-22.77 * *$ & 1,2 & -1.293 & $\begin{array}{c}Q(10)= \\
4.028 \\
{[0.776]}\end{array}$ & $\begin{array}{c}\mathrm{F}(5,1123 \\
)= \\
18.014 \\
{[0.0000]} \\
* *\end{array}$ & 1,1 & 1.338 & \begin{tabular}{|c|}
$\mathrm{F}(5,112$ \\
)$=$ \\
1.653 \\
{$[0.143]$}
\end{tabular} \\
\hline
\end{tabular}
result showed no heteroscedasticity proved by ARCH LM form GARCH model insignificant.

TABLE II: SUMMARY STATISTICS OF UNIT ROOT, ARMA, Q-TEST, ARCHLM AND GARCH values are in parentheses.

TABLE III: SUMMARY STATISTICS OF ARFIMA MODEL WITH ALl PERIOD

\begin{tabular}{|c|c|c|c|c|c|}
\hline \multirow{2}{*}{ Code } & \multicolumn{5}{|c|}{ ARFIMA } \\
\cline { 2 - 6 } & model & d-coeff. & AIC & ARCH 1-5 test & $\begin{array}{c}\text { Log } \\
\text { Likelihood }\end{array}$ \\
\hline ASEA & 1,2 & -0.088 & 1.543 & $\begin{array}{c}\mathrm{F}(5,1123)= \\
18.014 \\
{[0.0000]^{*}}\end{array}$ & -869.065 \\
& & & & & \\
& & & & & \\
\end{tabular}

Note: $*, * *$ and $* * *$ are significance at 10,5 and $1 \%$ levels, respectively; $\mathrm{p}-$ values are in parentheses.

The results of the ARFIMA model in Table III showed 
that the variable is stationary with d-coefficient between $0.5<\mathrm{d}$-coeff $<0.5$, revealing that there were significant long memory for ASEAN ETFs [24]. On the other hand, there is a presence anti-persistence for others ETFs. Furthermore, the testing results of ARCH-LM test found that no arch effect for all samples was rejected.

In Table IV, by using ARFIMA-FIGARCH model this study found that all data sample was stationary because $|d|-$ Arfima $<0.5$ [28].Thus, d-FIGARCH showed that ASEAN ETFs have strong volatility persistence because of $0<d<1$.

TABLE VI: SUMMARY STATISTICS OF ARFIMA-FIGARCH MODELS WITH ALL PERIOD

\begin{tabular}{|c|c|c|c|c|c|c|c|}
\hline \multirow{2}{*}{ Code } & \multicolumn{5}{|c|}{ ARFIMA-FIGARCH } & AIC & ARCH 1-5 test \\
\cline { 2 - 7 } & d-ARFIMA & d-FIGARCH & ARCH (Phi1) & GARCH (Beta1) & & Log Likelihood \\
\hline ASEA & -0.053 & 0.583 & 0.116 & 0.617 & 1.344 & $\mathrm{~F}(5,1121)=1.1983[0.3078]$ & -752.871 \\
\hline
\end{tabular}

TABLE V: SUMMARY STATISTICS OF ARFIMA-FIAPARCH MODELS WITH ALL PERIOD

\begin{tabular}{|c|c|c|c|c|c|c|c|}
\hline \multirow[t]{2}{*}{ Code } & \multicolumn{7}{|c|}{ ARFIMA-FIAPARCH } \\
\hline & d-ARFIMA & d-FIGARCH & APARCH (Gamma1) & APARCH (Delta) & AIC & ARCH test & Log Likelihood \\
\hline ASEA & $-0.060 *$ & $0.222 * * *$ & $0.910^{*}$ & $1.705 * * *$ & 1.312 & $\mathrm{~F}(5,112)=2.266[0.046]^{*}$ & -732.810 \\
\hline
\end{tabular}

TABLE VI: SUMMARY STATISTICS OF ARFIMA-HYGARCH MODELS WITH ALL PERIODS

\begin{tabular}{|c|c|c|c|c|c|c|c|c|c|}
\hline \multirow[t]{2}{*}{ Index } & \multicolumn{9}{|c|}{ ARFIMA-HYGARCH } \\
\hline & d-Arfima. & Model & d-hygarch & ARCH (Phi1) & GARCH (Beta1) & Log Alpha (HY) & AIC & ARCH 1-5 test: & Log Likelihood \\
\hline ASEA & -0.054 & 1,2 & $0.617 * *$ & 0.1073 & 0.637 & -0.012 & 1.345 & $\mathrm{~F}(5,112)=1.269[0.275]$ & -752.833 \\
\hline
\end{tabular}

Table V shown that $|d|$-Arfima $<0.5$ its means data sample stationary. Meanwhile d-FIGARCH 0.2219179 revealed that ASEAN ETFs have long memory, because when $0<d$ FIGARCH $<1$, It means that effect of a shock on the conditional variance decays at a hyperbolic rate [33], [34], [35]. When asymmetry parameter Gamma $\gamma>0$, negative shocks cause higher volatility than positive shocks, and visa versa. The FIAPARCH model is reduced the FIGARCH model, when $\delta=2$ and $\gamma=0$. Hence, it can be said that FIAPARCH model is superior to the FIGARCH model because it can evaluate both asymmetry and long memory in the volatility. The same result with Balibey\&Turkyilmaz used FIAPARCH $(1, d, 1)$ model with skewed student-t had better accuracy results in capture stylized facts in the volatility of Turkish Stock Market [36].

The results of ARFIMA-HYGARCH model can be seen in Table VI, ASEAN ETFs are stationary because dARFIMA showed $-0.5<d<0.5$ [24]. Furthermore, when Log $\alpha<1$ reduces to an autoregressive root, it becomes more stable than GARCH or IGARCH. Moreover, the results showed that data sample have long memory because of $0<d$ hygarch $\leq 1$ [32].

TABLE VII: COMPARISON LOG-LIKEHOOD ARFIMA, ARFIMA-FIGARCH,

\begin{tabular}{|c|c|c|c|c|}
\multicolumn{5}{c|}{ ARFIMA FIAPARCH, ARFIMA HYGARCH } \\
\hline \multirow{3}{*}{ Code } & ARFIMA & $\begin{array}{c}\text { ARFIMA- } \\
\text { FIGARCH }\end{array}$ & $\begin{array}{c}\text { ARFIMA- } \\
\text { FIAPARCH }\end{array}$ & $\begin{array}{c}\text { ARFIMA- } \\
\text { HYGARCH }\end{array}$ \\
\cline { 2 - 5 } & $\begin{array}{c}\text { Log } \\
\text { Likelihood }\end{array}$ & $\begin{array}{c}\text { Log } \\
\text { Likelihood }\end{array}$ & Log Likelihood & Log Likelihood \\
\hline ASEA & -869.06566 & -752.871 & -732.810 & -752.833 \\
& & & & \\
& & & & \\
\hline
\end{tabular}

Used Log-likelihood result compared four models for testing of long memory as shown in Table VII. The log likelihood value is always negative. When log likelihood has higher value, and closer to zero, this indicated a better fitting model Johnston and Di Nardo, and Fox [37], [38]. The bigger Log-likelihood measurement showed that ARFIMA-FIAPARCH model is the best model to reveal long memory and volatility for ASEAN ETFs.

\section{CONCLUSIONS}

In this paper has been used four models such as ARFIMA, ARFIMA-FIGARCH, ARFIMA-FIAPARCH, and ARFIMA-HYGARCH to analyze the long memory in volatility, and asymmetric effect of ASEAN exchangetraded fund. The result showed that ASEAN ETF have long memory in volatilities and asymmetric effect. Moreover, ARFIMA-FIAPARCH model is the best to analyze long memory and asymmetric volatility. the results of ARFIMAFIAPARCH revealed that ASEAN ETF have negative news impact on volatility. This result the same finding with Wiphatthanananthakula and Sriboonchitta that ARFIMAFIAPARCH which are capable of captured long memory and asymmetry in the conditional variance and power transformed conditional variance of process at Thailand volatility index. Balibey \& Turkyilmaz also revealed that FIAPARCH model have more accuracy results in capture stylized facts in the volatility of Turkish Stock Market [22], [36].

In summary, it can be said that ASEAN ETF returns exhibit asymmetry and have long memory. Long memory indicated that ASEAN ETF can be predicted.

Comparing the results of four long memory models, FIAPARCH $(1, d, 1)$ was preferable a model to analyze the long and short trading positions. In this sense, the findings of research can be evaluated by investors, financial risk managers, regulators and academicians.

\section{REFERENCES}

[1] D. B. Mazza, "Do ETFs increase correlations?" The Journal of Index Investing, vol. 3, no. 1, pp. 45-51, 2012.

[2] S. A. Schoenfeld, "ETFs offer the world to investor," ETFs and Indexing, vol. 1, pp. 111-117, 2001.

[3] S. Gao, "The new generation of investment funds," ETFs and Indexing, vol. 1, pp. 101-105, 2001.

[4] C. W. J. Granger, "Long memory relationships and the aggregation of dynamic models," Journal of Econometrics, vol. 14, pp. 227-238, 1980.

[5] C. W. J. Granger and R. Joyeux, "An introduction to long memory time series models and fractional differencing," Journal of Time Series Analysis, vol. 1, pp. 15-39, 1980. 
[6] J. R. M. Hosking, "Fractional differencing," Biometrika, vol. 68, pp. 165-176, 1981

[7] R. F. Engle, "Autoregressive conditional heteroscedasticity with estimates of the variance of United Kingdom inflation," Econometrica, vol. 50, no. 4, pp. 987-1007, 1982.

[8] T. Bollerslev, "Generalized autoregressive conditional heteroskedasticity," Journal of Econometrics, vol. 31, no. 3, pp. 307327, 1986.

[9] R. F. Engle and T. Bollerslev, "Modeling the persistence of conditional variances," Econometrica, vol. 50, pp. 1-50, 1986.

[10] B. P. Sivakumar and V. P. Mohandas, "Modeling and predicting stock returns using the ARFIMA-FIGARCH," World Congress on Nature \& Biologically Inspired Computing, NaBIC, pp. 896-901, 2009.

[11] R. T. Baillie, T. Bollerslev, and H. Mikkelsen, "Fractionally integrated generalized autoregressive conditional heteroskedasticity," Journal of Econometrics, vol. 74, pp. 3-30, 1996.

[12] S. H. Kang and S. M. Yoon, "Long memory properties in return and volatility: evidence from the korean stock market," Statistical Mechanics and Its Applications, vol. 385, no. 2, pp. 591-600, 2007.

[13] T. Bollerslev and H. Mikkelsen, "Modeling and pricing long memory in stock market volatility," Journal of Econometrics, vol. 73, no. 1, pp. 151-184, 1996.

[14] J. Davidson, "Moment and memory properties of linear conditional heteroscedasticity models, and a new model," Journal of Business \& Economic Statistics, vol. 22, no. 1, pp. 16-29, 2004.

[15] J. A. Gutierrez, V. Martinez, and Y. Tse, "Where does return and volatility come from? The case of Asian ETFs," International Review of Economics \& Finance, vol. 18, no. 4, pp. 671-679, 2009.

[16] H. C. Liu, S. M. Chiang, and N. Y. P. Cheng, "Forecasting the volatility of S\&P depositary receipts using GARCH-type models under intraday range-based and return-based proxy measures," International Review of Economics \& Finance, vol. 22, no. 1, pp. 7891, 2012.

[17] J. H. Chen and J. F. Diaz, "Long memory and shifts in the returns of green and non-green Exchange-Traded Funds (ETFs)," International Journal of Humanities and Social Science Invention, vol. 2, no. 10, pp. 29-32, 2013.

[18] E. Ruiz and H. Veiga, "Modelling long-memory volatilities with leverage effect: A-LMSV versus FIEGARCH," Computational Statistics \& Data Analysis, vol. 52, no. 6, pp. 2846-2862, 2008.

[19] Z. Ding and C. W. J. Granger, "Modeling volatility persistence of speculative returns: A new approach," Journal of Econometrics, vol 73, no. 1, pp. 185-215, 1996

[20] T. L. Tang and S. J. Shieh, "Long memory in stock index futures markets: A value-at-risk approach," Physica A: Statistical Mechanics and its Applications, vol. 366, pp. 437-448, 2006.

[21] E. Pelinescu and M. Acatrinei, "Modelling the high frequency exchange rate in Romania with FIGARCH," Procedia Economics and Finance, vol. 15 , pp. 1724-1731, 2014.

[22] C. Wiphatthanananthakul and S. Sriboonchitta, "ARFIMAFIGARCH and ARFIMA -FIAPARCH on Thailand Volatility Index," The Thailand Econometrics Society, vol. 2, no. 2, pp 280-294, 2010.

[23] G. E. P. Box and D. A. Pierce, "Distribution of the residual autocorrelations in autoregressive-integrated moving-average time series models," Journal of the American Statistical Association, vol. 65, pp. 1509-1526, 1970

[24] S. Paul, S. Viljoen, and Q. Morris, "A triptych on the USD-ZAR exchange rate dynamics," Journal of Money, Investment and Banking, vol. 9, pp. 95-102, 2009.
[25] J. K. Hsieh and C. F. Lin, "Long memory and regime switch," Taiwan Economic Review, vol. 32, pp. 193-232, 2004.

[26] B. J. Christensen, M. Ø. Nielsen, and J. Zhu, "Long memory in stock market volatility and the volatility-in-mean effect: The FIEGARCHM Model," Journal of Empirical Finance, vol. 17, no. 3, pp. 460-470, 2010.

[27] D. B. Nelson, "Conditional heteroskedasticity in asset returns: A new approach," Econometrica, vol. 59, no. 2, pp. 347-370, 1991

[28] P. Zaffaroni, "Stationary and memory of arch ( $\infty)$ models," Econometric Theory, vol. 20, pp. 147-160, 2004.

[29] Z. Ding, C. W. J. Granger, and R. F. Engle, "A long memory property of stock market returns and a new model," Journal of Empirical Finance, vol. 1, pp. 83-106, 1993.

[30] Y. K. Tse, The conditional heteroscedasticity of the yen-dollar exchange rate, mimeo, 1996,

[31] D. A. Dickey and W. A. Fuller, "Distribution of the estimators for autoregressive time series with a unit root," Journal of the American Statistical Association, vol. 74, no. 366a, pp. 427-431, 1979.

[32] W. Kwan, W. K. Li, and G. Li, "On the estimation and diagnostic checking of the ARFIMA-HYGARCH model," Computational Statistics \& Data Analysis, vol. 56, no. 11, pp. 3632-3644, 2012.

[33] E. Demireli, "Value at Risk (VAR) analysis and Long Memory: Evidence from FIAPARCH in Istanbul Stock Exchange," Atatürk Üniversitesi İktisadi ve İdari Bilimler Dergisi., vol. 24, no. 4, pp. 217 $228,2010$.

[34] S. H. Kang and S. M. Yoon, "Value-at-Risk analysis of the long memory volatility process: the case of individual stock returns," The Korean Journal of Finance, vol. 21, pp. 4-18, 2008

[35] Z. Mighri, K. Mokni, and F. Mansouri, "Empirical analysis of asymmetric long memory volatility models in value-at-risk estimation," The Journal of Risk, vol. 13, no. 1, pp. 55-128, 2010.

[36] M. Balibey and S. Turkyilmaz, "Value-at-Risk Analysis in the Presence of Asymmetry and Long Memory: The Case of Turkish Stock Market," International Journal of Economics and Financial Issues, vol. 4, no. 4, pp. 836-848, 2014.

[37] J. Johnston and J. Di Nardo, Econometric Methods Fourth Edition, New York, NY: The McGraw-Hill Companies, Inc, 1997.

[38] J. Fox, Applied regression analysis, linear models, and related methods, Thousand Oaks, CA: Sage Publications, 1997.

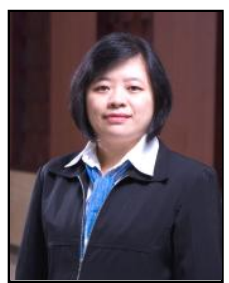

Maya Malinda was born in Bandung, Indonesia. She graduate from $\mathrm{PhD}$ in Business Program at Chung Yuan Christian University, Taiwan, R.O.C. She took her Master Degree in Bandung Institute of Technology Indonesia; her field was the Development Studies Graduate Program, in special topic Innovation and Entrepreneurship. She got a Bachelor Degree from Faculty of Economic Universitas Kristen Maranatha/Maranatha Christian University; Bandung, Indonesia with field of study was Management.

From 2008 to 2012, she was the secretary of Management Department, Faculty of Economics Maranatha Christian University. Leading 50 lecturers, 3 employees, and 1,778 students achieve Management Department's goals.

Ms Maya Malinda has professional certifications for financial planner (Certified Financial Planner, CFP® because she has a passion to inspire and to equip people to plan their finances goal.

Her research areas/interests: international finance, entrepreneurship, financial management and personal financial planning. 